\title{
Frailty and elderly in urology: implications for postoperative complications
}

\author{
Phil Hyun Song \\ Department of Urology, Yeungnam University College of Medicine, Daegu, Korea
}

Received: September 3, 2020

Revised: September 16, 2020

Accepted: September 17, 2020

Corresponding author:

Phil Hyun Song

Department of Urology, Yeungnam

University College of Medicine, 170

Hyeonchung-ro, Nam-gu, Daegu

42415 , Korea

Tel : +82-53-620-3693

Fax : +82-53-627-5535

E-mail : sph04@hanmail.net
The geriatric population is at a greater risk of postoperative complications than young adults. This risk is associated with the physiologic decline seen in this population known as frailty. Unlike fitter patients, frail patients who undergo operative treatment have a greater likelihood of developing postoperative complications and endure prolonged hospital stays. This circumstance is comparable to the urological status. Therefore, tolerable measurement of frailty as a domain of preoperative health status has been suggested to ascertain vulnerability in elderly patients. In this review, we will elaborate on the concept of frailty and examine its importance with respect to surgical complications, focusing on the urological status.

Keywords: Complications; Frailty; Postoperative; Urology

\section{Introduction}

The demographic composition of the surgical population changes with the aging of the population. Older adults account for an increasing proportion of the surgical population, with $>35 \%$ of all inpatient operations being performed in adults aged 65 years or older in the United States. This proportion is higher in medicine subspecialties, such as urology, where $65 \%$ of all surgeries are performed in adults aged 65 years and older [1] and is anticipated to increase in the future. This situation is similar in every country including South Korea. Therefore, it is essential to understand the unique physiology and characteristics of older adults to provide optimal urologic care for these patients.

The geriatric population is at a greater risk for postoperative complications than young adults. This risk is associated with the physiologic decline observed in this population known as frailty. Frailty is a state of decreased physiologic reserve that increases a patient's susceptibility to incapacity. Thus, by definition, frailty increases the risk of poor surgical outcomes. A few studies have reported outcomes, such as a higher risk of delirium, injury, intensive care unit (ICU) admissions, ICU stay, and death, in geriatric urologic patients than in young adults $[2,3]$.

Previous concepts of postoperative risk estimation, such as the American Society of Anesthesiology (ASA) physical status classification and European Cooperative Oncology Group (ECOG) performance, have focused on single-organ systems to determine the risk of adverse postoperative cardiac, hepatic, pulmonary, or renal events $[4,5]$. Although these algorithms continue to play a role in the postoperative risk estimation of urologic patients, frailty has covered these strategies as an effective, efficient, and global estimation for surgical risk and represents a notable paradigm shift for the anticipation of postoperative complications [6]. In this review, we will elaborate on the concept of frailty and examine its importance with respect to surgical complications, with a focus on urological status.

\section{Definition of frailty}

Although no single operational definition is all-encompassing, a clear conceptual framework for frailty has been established. Frailty 
is a state of extreme vulnerability to stressors that induces adverse health outcomes $[7,8]$. However, frailty is a complex, multidimensional, and cyclical state of decreased physiologic reserve that results in diminished resilience and adaptive capacity and increased vulnerability to stressors (Fig. 1) [9]. Frailty has also been related to the concept of health deficits, that, when accumulated over time, heightens an individual's vulnerability to adverse health outcomes [10].

The prevalence of frailty is high among the elderly and increases with age, as observed in $40 \%$ of patients aged 80 years or older compared with $10 \%$ of patients aged between 65 and 75 years [11]. Unlike fitter patients, frail patients who undergo surgery have a greater likelihood of developing postoperative complications, being discharged to care facilities, and having longer hospital stays. Postoperative complications can result in a series of events leading to loss of independence, decline in the quality of life, disability, increased healthcare costs, and even death $[2,3]$. Therefore, adequate measurement of frailty as a domain of preoperative health status has been proposed to ascertain vulnerability in elderly patients.

\section{Measurement of frailty}

Current recommendations state that all patients aged $>70$ years and those with significant weight loss $(>5 \%)$ due to chronic illness should be screened for frailty [9]. However, it is not clear which frailty measure is optimal for screening and assessment. Over 70 different tools exist to measure frailty, few of which have been proven, and they range from a single item to more than 90 items. They also range in their intended purpose, with some frailty systems being designed as screening tools to risk-stratify patients, and others as more formal frailty estimations aimed at guiding treatment strategy. A brief summary of the most commonly used frailty assessment tools is provided below.

\section{Individual assessment tools}

Using a single-item estimation tool is a quick and easy means to quantify a patient's level of frailty. The most commonly used single-item tools that have been demonstrated to be reliable predictors of frailty are gait speed (the measured time it takes for a patient to walk a 5-m distance), grip strength (a marker of frailty via universal loss of muscle mass or myopathy associated with decreased physiologic reserve), and Timed Up-and-Go score (the measured time it takes for a patient to rise from a chair, walk 10 feet, turn around, and return to being seated) [12-14].

Although these single-item assessments can be convenient to use in a busy and time-constrained circumstance, they can also lack sensitivity and specificity and, when in isolation, should be used with caution [6].

\section{FRAIL scale and Vulnerability Elders Survey-13}

Developed by the Geriatric Advisory Panel of the International

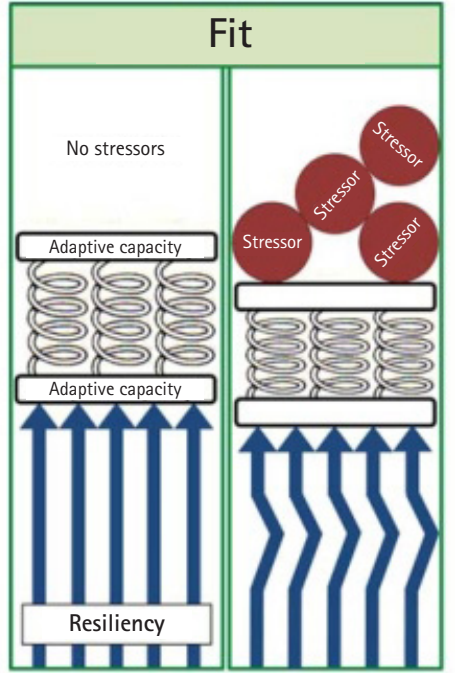

Robust adaptive capacity and resiliency to stressors

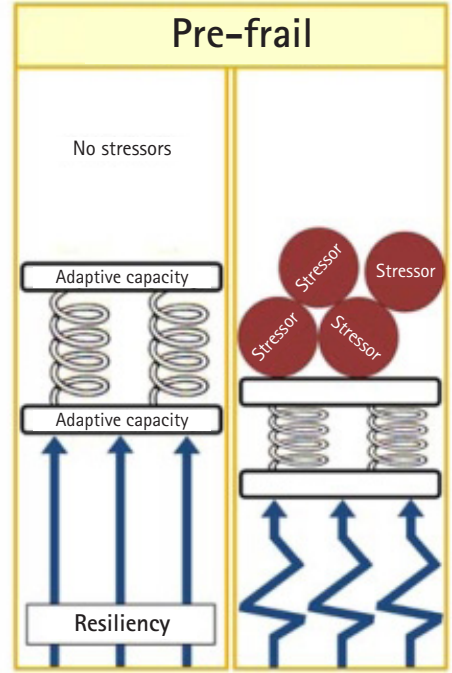

Weak adaptive capacity and resiliency to stressors

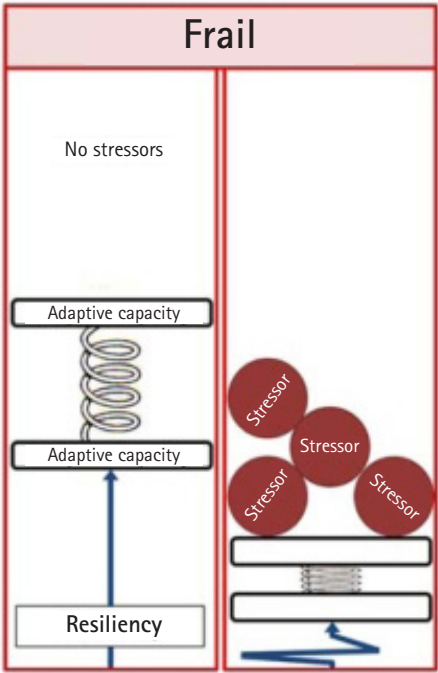

Favorable outcomes

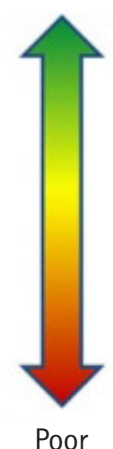

outcomes

Fig. 1. Model for defining frailty. Fit patients have robust adaptive capacity and resilience to stressors, which lead to more favorable outcomes. Pre-frail patients have weakened adaptive capacity and resilience to stressors, and frail patients have poor adaptive capacity and resilience to stressors. Adapted from Ethun et al. [9] with permission of Wiley. 
Academy of Nutrition and Aging, the fatigue, resistance, ambulation, illness, and loss of weight (FRAIL) scale is a validated screening method consisting of five straightforward questions (Table 1) $[9,15]$. Because it can be self-administered and does not crave a face-to-face examination, this tool can be an efficient and cost-effective tool to screen large groups of patients for frailty. However, this scale is applied most frequently in primary care or community environments and has not been investigated extensively as a screening method for patients with cancer $[9,16]$.

The Vulnerability Elders Survey-13 (VES-13) is also a self-administered survey consisting of 13 items: one item for age and 12 for self-rated health, physical ability, and functional performance. However, unlike the FRAIL scale, this practical screening tool can be used as a reliable marker of frailty in patients with cancer. Despite these advantages, the VES-13 may be inaccurate because of patients' overestimation of their own competencies $[17,18]$.

\section{Phenotypic frailty}

Phenotypic frailty is one of the most widely used frailty assessment tools in oncology and has been identified by the American Geriatric Society and the American College of Surgeons (ACS) as an adequate strategy for preoperatively measuring elderly patients. It is based on the notion that frailty results from age-associated biological changes across multiple domains, such as nutrition and energy metabolism. This method consists of five items (weight, strength, energy, speed, and activity) and needs a combination of question-

Table 1. FRAIL scale

\begin{tabular}{ll}
\hline Letter & \multicolumn{1}{c}{ Item (questionnaire) } \\
\hline $\mathrm{F}$ & Fatigue (do you feel tired most or all the time?) \\
$\mathrm{R}$ & Resistance (can you climb one flight of stairs without difficulty?) \\
$\mathrm{A}$ & Ambulation (can you walk one block without assistance?) \\
$\mathrm{I}$ & IIIness (do you have greater than five illnesses?) \\
$\mathrm{L}$ & $\begin{array}{c}\text { Loss of weight (have you lost }>5 \% \text { of your usual weight in the } \\
\text { last year?) }\end{array}$ \\
\hline
\end{tabular}

Scoring: 0 indicates robust, 1-2 indicates pre-frail, and 3 indicates frail. Adapted from Ethun et al. [9] with permission of Wiley.

Table 2. Phenotypic frailty

\begin{tabular}{|c|c|}
\hline Item & Contents \\
\hline Weight loss & $\geq 10 \mathrm{lb}$ weight loss in the past years \\
\hline Weakness & $\begin{array}{l}\text { Grip strength in lowest } 20 \% \text { based on sex and body } \\
\text { mass index }\end{array}$ \\
\hline Exhaustion & $\begin{array}{l}\text { Self-reported exhaustion, fatigue, and/or loss of } \\
\text { motivation }\end{array}$ \\
\hline Slow gait speed & Time it takes to walk $15 \mathrm{ft}$ at normal speed \\
\hline Low activity & $\begin{array}{l}\text { Kilocalories of expenditure based on self-reported } \\
\text { physical activities }\end{array}$ \\
\hline
\end{tabular}

Adapted from Ethun et al. [9] with permission of Wiley. naires and in-office estimations (Table 2) [9,19].

\section{Frailty index and modified frailty index}

The frailty index (FI) was initiated from the Canadian Study of Health and Aging and is based on an accumulative deficit model [20]. This method proposes that the accumulation of medical, functional, and social shortfalls over an individual's lifetime induces a nonspecific, age-associated vulnerability, or, in other words, frailty [8]. The original FI includes 70 items, which vary from vague to specific symptoms, signs, diseases, and disabilities. Although many of the included items can be found in patient charts, several need more cumbersome and labor-intensive estimations, which makes FI less attractive in clinical practice. Therefore, Obeid et al. [21] proposed a modified FI (mFI), which maps the 70 variables from the original FI into 11 preexisting variables from the National Surgical Quality Improvement Program (NSQIP) database and has since been backed by the ACS (Table 3) [9] .

\section{Comprehensive geriatric assessment}

Comprehensive geriatric assessment (CGA), a multidimensional measurement process for identifying and managing elderly patients, is one of the most extensively investigated and used methods in oncology. Using principles similar to those of the cumulative deficit model, the CGA focuses on some domains of a patient's psychosocial, medical, and functional abilities and can be a reliable assessment of frailty when used as a screening method in patients with cancer [22]. However, with 64 instruments of assessment, managing a full CGA can take hours to complete and is often impractical; hence, the CGA was altered to address these issues. For example, the Cancer-Specific Geriatric Assessment is a brief and

Table 3. Modified frailty index

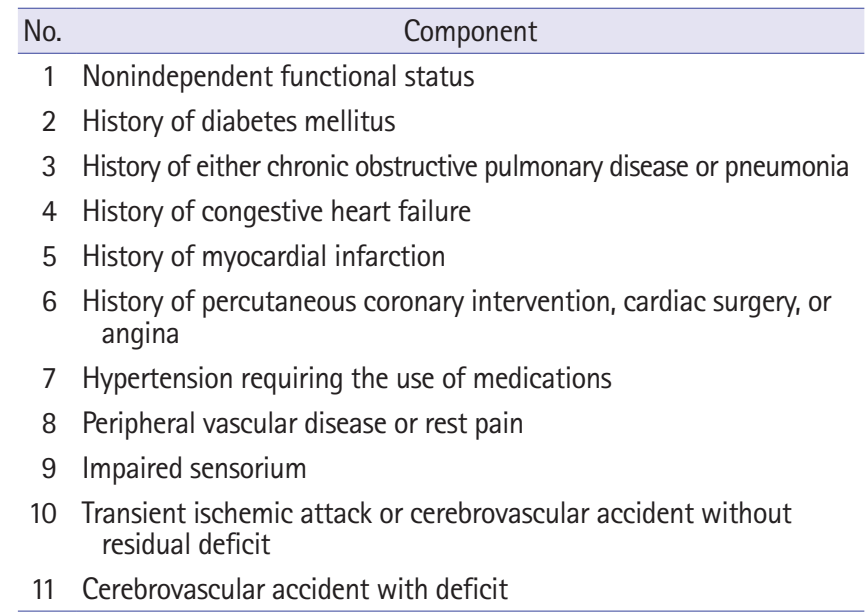

The proposed cutoff score (total number of variables present/total number of variables assessed) $>0.36$ indicates frail. Adapted from Ethun et al. [9] with permission of Wiley. 
more focused method that combines both self-administered and in-office assisted estimations [23]. It contains six of the nine domains from the full CGA, and the methods for measuring those domains were specifically chosen for their reliability, brevity, validity, and prognostic ability in patients with cancer [24].

\section{Frailty and postoperative complications, especially with respect to urological surgery}

The decision regarding a patient's "fitness" for operative treatment has traditionally been based on fairly subjective and particularly simplistic assessments, which can be limited in their capacity to predict postoperative morbidity and mortality [13]. Because it transcends age or any single-organ system, frailty has been shown to be a stronger predictor of postoperative complications than some previous surgical risk-assessment methods [25,26]. Revenig et al. [27] reported that frailty was even predictive of postoperative complications among patients undergoing minimally invasive abdominal surgery.

Although less well investigated, the value of frailty, especially in urological oncologic surgery, is increasingly being investigated. It has been demonstrated that frailty is associated with worse longterm and short-term survival in patients undergoing surgery for various malignancies. For example, when frail patients were assessed using the NSQIP mFI, they demonstrated higher 30-day mortality rates than nonfrail patients undergoing surgery for bladder cancer (3.5\% vs. $1.8 \%$; $p=0.01$ ) [28]. Expanding the mFI to include 15 variables, Lascano et al. [29] found that, in patients undergoing operative treatments for urologic malignancies, such as cystectomy, prostatectomy, nephrectomy, and nephroureterectomy, there was a two to six times increased risk of death within 30 days for every 0.05 increase in the calculated mFI compared with that in nonfrail patients $(\mathrm{mFI}<0.05)$. They also reported that patients undergoing operative treatments for urologic malignancies with high frailty ( $\mathrm{mFI}>0.20)$ had a significantly increased risk of major side effects (Clavien-Dindo grade IV) compared with nonfrail patients (odds ratio, 3.70; 95\% confidence interval, 2.87-7.79; $p<0.0005)$.

The $\mathrm{mFI}$ has also been used to evaluate patients treated with robotic-assisted radical prostatectomy (RARP) for prostate cancer. Levy et al. [30] also queried the NSQIP database to create a dataset of 23,000 patients who underwent RARP. An mFI score of $\geq 3$ was related to a 12 -fold increased risk of a Clavien-Dindo grade IV event compared with that in nonfrail patients.

\section{Conclusion}

Current knowledge on preoperative geriatric estimation in urologic patients is sparse. Frailty is emerging as one of the most significant predictors of postoperative complications, disease progression, and death. Therefore, preoperative recognition of frailty in such patients seems to be an important method in urological practice. Moreover, adequate stratification of preoperative frailty may induce a decrease in postoperative complications. It is also important that high-risk patients are routinely instructed to undergo training such as physical therapy, walking, and use of incentive spirometry in an effort to reduce postoperative complications. Thus, further research in urological environments, especially in multicenter randomized controlled trials, is required to develop a standardized cutoff value for frailty to provide better urologic patient care.

\section{Acknowledgments}

\section{Conflicts of interest}

No potential conflict of interest relevant to this article was reported.

\section{ORCID}

Phil Hyun Song, https://orcid.org/0000-0002-3801-258X

\section{References}

1. Hall MJ, DeFrances CJ, Williams SN, Golosinskiy A, Schwartzman A. National Hospital Discharge Survey: 2007 summary. Natl Health Stat Report 2010;(29):1-20.

2. Tognoni P, Simonato A, Robutti N, Pisani M, Cataldi A, Monacelli F, et al. Preoperative risk factors for postoperative delirium (POD) after urological surgery in the elderly. Arch Gerontol Geriatr 2011;52:e166-9.

3. Bjurlin MA, Goble SM, Fantus RJ, Hollowell CM. Outcomes in geriatric genitourinary trauma. J Am Coll Surg 2011;213:41521.

4. Neuman MD, Bosk CL. What we talk about when we talk about risk: refining surgery's hazards in medical thought. Milbank Q2012;90:135-59.

5. Fleisher LA, Fleischmann KE, Auerbach AD, Barnason SA, Beckman JA, Bozkurt B, et al. 2014 ACC/AHA guideline on perioperative cardiovascular evaluation and management of patients undergoing noncardiac surgery: a report of the American College of Cardiology/American Heart Association Task Force on practice guidelines. J Am Coll Cardiol 2014;64:e77-137.

6. Townsend NT, Robinson TN. Surgical risk and comorbidity in 
older urologic patients. Clin Geriatr Med 2015;31:591-601.

7. Lu J, Cao LL, Zheng CH, Li P, Xie JW, Wang JB, et al. The preoperative frailty versus inflammation-based prognostic score: which is better as an objective predictor for gastric cancer patients 80 years and older? Ann Surg Oncol 2017;24:754-62.

8. Robinson TN, Walston JD, Brummel NE, Deiner S, Brown CH 4th, Kennedy M, et al. Frailty for surgeons: review of a National Institute on Aging conference on frailty for specialists. J Am Coll Surg 2015;221:1083-92.

9. Ethun CG, Bilen MA, Jani AB, Maithel SK, Ogan K, Master VA. Frailty and cancer: implications for oncology surgery, medical oncology, and radiation oncology. CA Cancer J Clin 2017; 67:362-77.

10. Cohen RR, Lagoo-Deenadayalan SA, Heflin MT, Sloane R, Eisen I, Thacker JM, et al. Exploring predictors of complication in older surgical patients: a deficit accumulation index and the Braden Scale. J Am Geriatr Soc 2012;60:1609-15.

11. Collard RM, Boter H, Schoevers RA, Oude Voshaar RC. Prevalence of frailty in community-dwelling older persons: a systematic review. J Am Geriatr Soc 2012;60:1487-92.

12. Buettner S, Wagner D, Kim Y, Margonis GA, Makary MA, Wilson $\mathrm{A}$, et al. Inclusion of sarcopenia outperforms the modified frailty index in predicting 1-year mortality among 1,326 patients undergoing gastrointestinal surgery for a malignant indication.J Am Coll Surg 2016;222:397-407.

13. Huisman MG, Audisio RA, Ugolini G, Montroni I, Vigano A, Spiliotis J, et al. Screening for predictors of adverse outcome in onco-geriatric surgical patients: a multicenter prospective cohort study. Eur J Surg Oncol 2015;41:844-51.

14. Chung CJ, Wu C, Jones M, Kato TS, Dam TT, Givens RC, et al. Reduced handgrip strength as a marker of frailty predicts clinical outcomes in patients with heart failure undergoing ventricular assist device placement. J Card Fail 2014;20:310-5.

15. Abellan van Kan G, Rolland YM, MorleyJE, Vellas B. Frailty: toward a clinical definition. J Am Med Dir Assoc 2008;9:71-2.

16. Woo J, Yu R, Wong M, Yeung F, Wong M, Lum C. Frailty screening in the community using the FRAIL scale. J Am Med Dir Assoc 2015;16:412-9.

17. Saliba D, Elliott M, Rubenstein LZ, Solomon DH, Young RT, Kamberg CJ, et al. The Vulnerable Elders Survey: a tool for identifying vulnerable older people in the community. J Am Geriatr Soc 2001;49:1691-9.

18. Revenig LM, Canter DJ, Henderson MA, Ogan K, Kooby DA, Maithel SK, et al. Preoperative quantification of perceptions of surgical frailty. J Surg Res 2015;193:583-9.

19. Li JL, Henderson MA, Revenig LM, Sweeney JF, Kooby DA, Maithel SK, et al. Frailty and one-year mortality in major in- tra-abdominal operations. J Surg Res 2016;203:507-12.

20. Rockwood K, Song X, MacKnight C, Bergman H, Hogan DB, McDowell I, et al. A global clinical measure of fitness and frailty in elderly people. CMAJ 2005;173:489-95.

21. Obeid NM, Azuh O, Reddy S, Webb S, Reickert C, Velanovich $\mathrm{V}$, et al. Predictors of critical care-related complications in colectomy patients using the National Surgical Quality Improvement Program: exploring frailty and aggressive laparoscopic approaches. J Trauma Acute Care Surg 2012;72:878-83.

22. Kellen E, Bulens P, Deckx L, Schouten H, Van Dijk M, Verdonck I, et al. Identifying an accurate pre-screening tool in geriatric oncology. Crit Rev Oncol Hematol 2010;75:243-8.

23. Hamaker ME, Jonker JM, de Rooij SE, Vos AG, Smorenburg $\mathrm{CH}$, van Munster BC. Frailty screening methods for predicting outcome of a comprehensive geriatric assessment in elderly patients with cancer: a systematic review. Lancet Oncol 2012; 13:e437-44.

24. White JV, Guenter P, Jensen G, Malone A, Schofield M; Academy of Nutrition and Dietetics Malnutrition Work Group, et al. Consensus statement of the Academy of Nutrition and Dietetics/American Society for Parenteral and Enteral Nutrition: characteristics recommended for the identification and documentation of adult malnutrition (undernutrition). J Acad Nutr Diet 2012;112:730-8.

25. Arya S, Kim SI, Duwayri Y, Brewster LP, Veeraswamy R, Salam A, et al. Frailty increases the risk of 30-day mortality, morbidity, and failure to rescue after elective abdominal aortic aneurysm repair independent of age and comorbidities. J Vasc Surg 2015; 61:324-31.

26. Jung HW, Jang IY, Lee YS, Lee CK, Cho EI, Kang WY, et al. Prevalence of frailty and aging-related health conditions in older Koreans in rural communities: a cross-sectional analysis of the aging study of Pyeongchang rural area. J Korean Med Sci 2016; 31:345-52.

27. Revenig LM, Canter DJ, Master VA, Maithel SK, Kooby DA, Pattaras JG, et al. A prospective study examining the association between preoperative frailty and postoperative complications in patients undergoing minimally invasive surgery. J Endourol 2014;28:476-80.

28. Chappidi MR, Kates M, Patel HD, Tosoian JJ, Kaye DR, Sopko NA, et al. Frailty as a marker of adverse outcomes in patients with bladder cancer undergoing radical cystectomy. Urol Oncol 2016;34:256.

29. Lascano D, Pak JS, Kates M, Finkelstein JB, Silva M, Hagen E, et al. Validation of a frailty index in patients undergoing curative surgery for urologic malignancy and comparison with other risk stratification tools. Urol Oncol 2015;33:426. 
30. Levy I, Finkelstein M, Bilal KH, Palese M. Modified frailty index associated with Clavien-Dindo IV complications in robot-assist- ed radical prostatectomies: a retrospective study. Urol Oncol 2017;35:425-31. 